\title{
Inhibitors in Geman Hemophilia A Patients Treated with a Double Virus Inactivated Factor VIII Concentrate Bind to the C2 Domain of FVIII light Chain
}

\author{
R. La ub ${ }^{1}$, M. Di Giambattista ${ }^{1}$, P. Fondu ${ }^{2}$, H.-H. Bra ckmann ${ }^{3}$, H. Lenk ${ }^{4}$, E. L. Sa enko ${ }^{5}$, \\ M. Felch ${ }^{5}$, D. Sc andella ${ }^{5}$
}

From the ${ }^{1}$ Red Cross, Brussels, Belgium; ${ }^{2}$ Hôp ital Universita ire Brugma nn, Brussels; ${ }^{3}$ University of Bonn, Gema ny, ${ }^{4}$ University of Leipzig, Germany; and ${ }^{5}$ Americ an Red Cross, Rockville, MD, USA

\section{Summary}

To reduce the risk of transmission of hepatitis A virus, an Octapharma produced factor VIII (fVIII) concentrate treated with solvent detergent (FVIII-SD) was further pasteurized after purification. This product, Octavi SDPlus (FVIII-SDP), was marketed in Europe in 1993 to 1995. Inhibitors appeared from September to October, 1995, in 12 of 109 previously treated German hemophilia A patients. A study of similarly treated Belgian patients, who also developed inhibitors, had shown antibodies to the fVIII light chain (domains A3-C1-C2) only. In the present study, the epitope specificity of 8 German inhibitor plasmas was also found to be restricted to the light chain. In radioimmunoprecipitation assays to localize the light chain epitope(s), antibody binding to heavy chain (domains A1-A2-B) was 11-148 fold lower than to the $\mathrm{C} 2$ domain, and binding to recombinant $\mathrm{A} 3-\mathrm{C} 1$ was barely detectable. These results were supported by $>95 \%$ neutralization of a high responder inhibitor titer by the $\mathrm{C} 2$ domain.

\section{Introduction}

The development of antibodies (inhibitors) that inactivate blood coagulation factor VIII (fVIII) and impair fVIII therapy is a serious complication in the treatment of hemophilia A. In one study, 17 of 71 $(23.9 \%)$ of previously untreated severe hemophiliacs that received only recombinant fVIII developed an inhibitor. All of the 17 patients who developed inhibitors did so in $\leq 50$ exposure days (1).

The association between a particular fVIII concentrate and development of inhibitors was first reported after the introduction of a plasma derived fVIII product purified by controlled-pore silica adsorption and pasteurized $\left(60^{\circ} \mathrm{C}, 10 \mathrm{~h}\right)$ for viral inactivation, FVIII CPS-P in The Netherlands (2) and FVIII P in Belgium (3). This inhibitor outbreak occurred in 19 hemophiliacs of whom 15 had $\geq 200$ exposure days to other fVIII products without developing an inhibitor. Fifteen of 17 inhibitors in the FVIII CPS-P treated patients arose after >50 exposure days (mean 157), which is also unusual. These inhibitors disappeared in all but one case after the patients were switched to other fVIII concentrates, demonstrating the direct role of FVIII CPS-P in the immune response (4).

A possible link between outbreaks of hepatitis A in hemophilia A patients who received solvent detergent treated fVIII in Europe was suggested (5). To address this problem, a new double virus inactivated

Correspondence to: Dr. D. Scandella, American Red Cross, 15601 Crabbs Branch Way, Rockville, MD 20855, USA - Tel.: +1 301738 0750; FAX Number: +1 3017380794
fVIII concentrate (Bisinact in Belgium and Octavi SDPlus elsewhere in Europe) purified by ion exchange chromatography and treated by solvent-detergent and pasteurization $\left(63^{\circ} \mathrm{C}, 10 \mathrm{~h}\right)$ was introduced in 1995. Both concentrates were produced by the same manufacturing process from cryoprecipitate of German or Belgian plasma. Similarly to FVIII CPS-P, FVIII-SDP induced an inhibitor outbreak in multitransfused hemophiliacs, and the inhibitors disappeared after patients were switched to other fVIII products (6).

The fVIII protein consists of a series of homologous domains arranged in the order A1-A2-B-A3-C1-C2 (7), and it circulates as a heterodimer of a heavy chain (A1-A2-B) and a light chain (A3-C1-C2). The epitope specificity of the fVIII CPS-P induced anti fVIII antibodies was restricted to the $\mathrm{C} 2$ domain in radioimmunoprecipitation assays (8). These properties were seen in only 1 of 34 hemophiliacs who developed inhibitors early in their treatment with other fVIII products, but they were common in individuals with autoimmune anti fVIII antibodies $(10 / 21)(9)$.

A more recent study of Belgian inhibitors that appeared after treatment with FVIII-SDP demonstrated that the anti fVIII antibodies bound mainly to the light chain (6). We have tested a similar group of FVIIISDP induced German inhibitor plasmas to further determine epitope specificity within the light chain and reactivity with a range of other fVIII concentrates. The predominance of anti $\mathrm{C} 2$ antibodies among the FVIII CPS-P induced inhibitors suggested that the FVIII-SDP inhibitors, which are light chain specific (6), may also be primarily $\mathrm{C} 2$ specific, and we have tested this hypothesis in our study.

\section{Materials and Methods}

Factor VIII concentrates, von Willebrand factor, and antibodies. The source and properties of each fVIII concentrate are summarized in Table 1. Recombinate is the only fVIII purified to homogeneity, and it was provided without albumin by Baxter/Healthcare, Glendale, CA, USA. The AP9 anti fVIII antibodies were raised against A3 domain synthetic peptide 1797-1815 in rabbits, and the $\operatorname{IgG}$ was purified by affinity chromatography on Sepharose coupled to the peptide. Anti A3 monoclonal antibody (MoAb) CLB-CAg A was generously provided by Dr. Jan van Mourik, Netherlands Red Cross.

FVIII and von Willebrand factor assays. FVIII activity (IU/ml) was measured by the chromogenic assay Coatest FVIII (Chromogenix, Mölndal, Sweden) using the 3rd international fVIII standard (1993). von Willebrand factor (vWf) concentration (IU/ml) was determined by enzyme linked immunosorbent assay (ELISA) (10) and by ristocetin cofactor activity (11) (European Pharmacopea). Inhibitor titers were measured by the Bethesda assay (12).

Activation of factor VIII by $\alpha$-thrombin. FVIII-SD, Bisinact, Octavi SDPlus, or Recombinate were reconstituted in water to a concentration of 200 IU fVIII/ml. Purified bovine $\alpha$-thrombin (108 U/mg; Sigma, St. Louis, MO, USA) was added to a final ratio of $0.008 \mathrm{U} / \mathrm{IU}$ fVIII for $30 \mathrm{~min}$ at $25^{\circ} \mathrm{C}$. The reaction was stopped by adding $1 / 4$ volume reducing buffer $(250 \mathrm{mM}$ Tris-HCl, $\mathrm{pH} 6.8$, 
Table 1 Characteristics of fVIII concentrates

\begin{tabular}{|l|c|c|c|c|}
\hline \multicolumn{1}{|c|}{$\begin{array}{c}\text { Factor VIII } \\
\text { Product }\end{array}$} & Source & Plasma source & $\begin{array}{c}\text { Viral } \\
\text { inactivation }\end{array}$ & $\begin{array}{c}\text { FVII specific } \\
\text { activity (IU/mg) }\end{array}$ \\
\hline FVIII-SD & DCF, Brussels & Belgium & SD & 105 \\
FVII-THP & LFB, Lille & France & SD & 115 \\
Haemoctin & $\begin{array}{c}\text { Biotest, } \\
\text { Dreieich }\end{array}$ & Germany & $\begin{array}{c}\text { SD, dry heat } \\
100^{\circ} \mathrm{C}, 30 \text { min. }\end{array}$ & 110 \\
$\begin{array}{l}\text { Bisinact, Octavi } \\
\text { SDPlus } \\
\text { (FVIII-SDP) }\end{array}$ & $\begin{array}{c}\text { Octapharma, } \\
\text { Vienna }\end{array}$ & $\begin{array}{c}\text { Germany } \\
\text { Belgium }\end{array}$ & $\begin{array}{c}\text { SD, Pasteurized } \\
63^{\circ} \mathrm{C}, 10 \text { hrs. }\end{array}$ & 120 \\
Recombinate & $\begin{array}{c}\text { Baxter/Hyland, } \\
\text { Glendale, CA }\end{array}$ & NA & None & $\geq 2000$ \\
\hline
\end{tabular}

All fVIII products except Recombinate (recombinant fVIII) were derived from human plasma. Recombinate, was provided from a highly purified fVIII fraction before addition of albumin. SD (solvent detergent), P (pasteurized), NA (not applicable)

$8 \%$ SDS, $200 \mathrm{mM}$ dithioerythritol, $40 \%$ glycerol) and heating at $95^{\circ} \mathrm{C}$ for $4 \mathrm{~min}$.

Immunoblotting. Methods for these procedures were previously described (6). Samples of fVIII concentrates containing 2.7 IU fVIII per lane, with or without thrombin activation as above, were analyzed by SDS $8 \%$ polyacrylamide gel electrophoresis (SDS-PAGE) under reducing conditions. After electrophoretic transfer of the proteins to nitrocellulose, the membrane was incubated overnight at room temperature with $5 \mu \mathrm{g} / \mathrm{ml}$ AP9 rabbit anti fVIII antibodies or a $1 / 5$ dilution of inhibitor plasma. Antibody binding was detected with $0.6 \mu \mathrm{g} / \mathrm{ml}$ biotinylated MoAb to rabbit IgG (Sigma) or $0.4 \mu \mathrm{g} / \mathrm{ml}$ biotinylated goat anti human IgG (Sigma) followed by $0.4 \mathrm{mg} / \mathrm{ml}$ streptavidin-peroxidase conjugate (Sigma). Bound peroxidase was measured by absorbance at $410 \mathrm{~nm}$ in $0.5 \mathrm{mg} / \mathrm{ml}$ 4-chloro-1-naphthol (BioRad, Hercules, CA, USA), $0.015 \%$ $\mathrm{H}_{2} \mathrm{O}_{2}, 20 \mathrm{mM}$ Tris- $\mathrm{HCl}$, pH 7.5, and $0.5 \mathrm{M} \mathrm{NaCl}$. Identification of anti vWf antibodies was performed in similar assays using $103 \mu \mathrm{g} / \mathrm{ml}$ anti vWf monoclonal antibody (MoAb) QED 10103 (QED Bioscience, San Diego, CA, USA) and $v W f$ of $>95 \%$ purity as a positive control. Proteins were stained by Coomassie blue.

Expression of rfVIII fragments. Construction of expression vectors for the A2 (13) and C2 (14) domain cDNAs and recombinant polypeptide production in Sf9 insect cells $(9)$ were described $(14,15)$. A construct encoding the A3-C1 domains preceded by the interferon signal peptide was expressed in Chinese hamster ovary cells (16).

Protein purification and radiolabeling. These methods were described in detail (17). Molar concentrations of polypeptides were calculated using the molecular mass derived from the translated cDNA sequence (18). Purity of all proteins was $>95 \%$ by SDS-PAGE and Coomassie blue or silver staining. A3-C1 was not purified. FVIII heavy chain $(6 \mu \mathrm{g})$ was labeled for $3 \mathrm{~min}$ to a specific radioactivity of $18.3 \mu \mathrm{Ci} / \mu \mathrm{g}$ and $4 \mu \mathrm{g} \mathrm{C} 2$ domain for $6 \mathrm{~min}$ to $7.3-9.0 \mu \mathrm{Ci} / \mu \mathrm{g}$. The $\mathrm{CHO}$ cell line expressing A3-C1 was labeled with $250 \mu \mathrm{Ci}$ Tran ${ }^{35} \mathrm{~S}$-label (ICN Biomedicals, Costa Mesa, CA, USA) as described (16).

Inhibitor neutralization assay. This assay was previously described (15). Briefly, inhibitor plasma (2 to $4 \mathrm{BU} / \mathrm{ml}$ ) was added to increasing concentrations of purified fVIII polypeptides and incubated at $37^{\circ} \mathrm{C}$ for $2 \mathrm{~h}$. Normal pooled plasma was added and incubated at $37^{\circ} \mathrm{C}$ for an additional hour. The inhibitor titer determined in the Bethesda assay (12) was expressed as a percentage of a control in which no fVIII polypeptide was added. The percentage neutralization is 100 minus this number.

Immunoprecipitation assays. Details were described previously (17). Duplicate dilutions of inhibitor plasmas were mixed with ${ }^{125}$ I-heavy chain or ${ }^{125} \mathrm{I}-\mathrm{C} 2$ domain $(0.75 \mathrm{nM}$ final concentration). Immune complexes were bound to Protein G Sepharose (Pharmacia Biotech, Uppsala, Sweden), followed by centrifugation and 3 washes. The total and Protein $\mathrm{G}$ bound radioactivity were measured in a gamma counter. The mean of 4 controls without antibody was subtracted from values for test samples. Immunoprecipitation units/ml (IPU/ml) were calculated as follows: (average bound/total ${ }^{125}$ I-fVIII polypeptide minus background $\times$ plasma dilution). Undiluted inhibitor plasma $(20 \mu \mathrm{l})$ was added to $100 \mu \mathrm{l}{ }^{35} \mathrm{~S}-\mathrm{A} 3-\mathrm{C} 1$ in growth medium, immunoprecipitation was performed, and detection of bound protein was by SDS-PAGE and autoradiography (16).
Table 2 Characteristics of study patients

\begin{tabular}{|c|c|c|c|c|c|}
\hline Patient & Year of birth & $\begin{array}{c}\text { Previous } \\
\text { inhibitor } \\
\text { history }\end{array}$ & $\begin{array}{c}\text { Treatment } \\
\text { weeks }\end{array}$ & $\begin{array}{c}\text { Exposure days } \\
\text { FVIII-SDP or } \\
\text { FVIII-THP }\end{array}$ & $\begin{array}{c}\text { Maximum } \\
\text { Inhibitor titer } \\
\text { (BU/ml) }\end{array}$ \\
\hline G1 & 1955 & - & 76 & 300 & 2.1 \\
G2 & 1987 & + & 45 & 134 & 7.6 \\
G3 & 1971 & - & 36 & 256 & 3.4 \\
G4 & 1987 & + & 37 & 154 & 2.9 \\
G5 & 1960 & - & 30 & 84 & 2.0 \\
G6 & 1978 & - & 19 & 124 & 5.2 \\
G7 & 1987 & + & 32 & 114 & 2.2 \\
G8 & 1980 & - & 87 & 273 & 188 \\
\hline B1 & 1993 & - & 56 & $144^{\mathrm{I}}$ & 35 \\
\hline
\end{tabular}

The patients from Germany $(\mathrm{G})$ and Luxembourg (B) are severe hemophiliacs ( $<2 \% \mathrm{FVIII}$ activity). Treatment weeks and exposure days to FVIII-SDP before inhibitor detection is listed for the G patients and to FVIII-THP for patient Bl treated exclusively with this concentrate. The plasmas tested were taken at the inhibitor peak and tested by the Bethesda assay (BU/ml).

\section{Results}

Description of patients. Eight severe hemophilia A patients were treated in two German hemophilia centers: G1 to G7 in Bonn and G8 in Leipzig (Table 2). They were previously treated patients (PTP) with $>1000$ exposure days to fVIII and routinely treated by prophylaxis. Patients G2, G4 and G7 had a previous inhibitor history during treatment with other fVIIIs, but the inhibitor disappeared before the start of treatment with Octavi SDPlus or Bisinact. As Bisinact and Octavi SDPlus

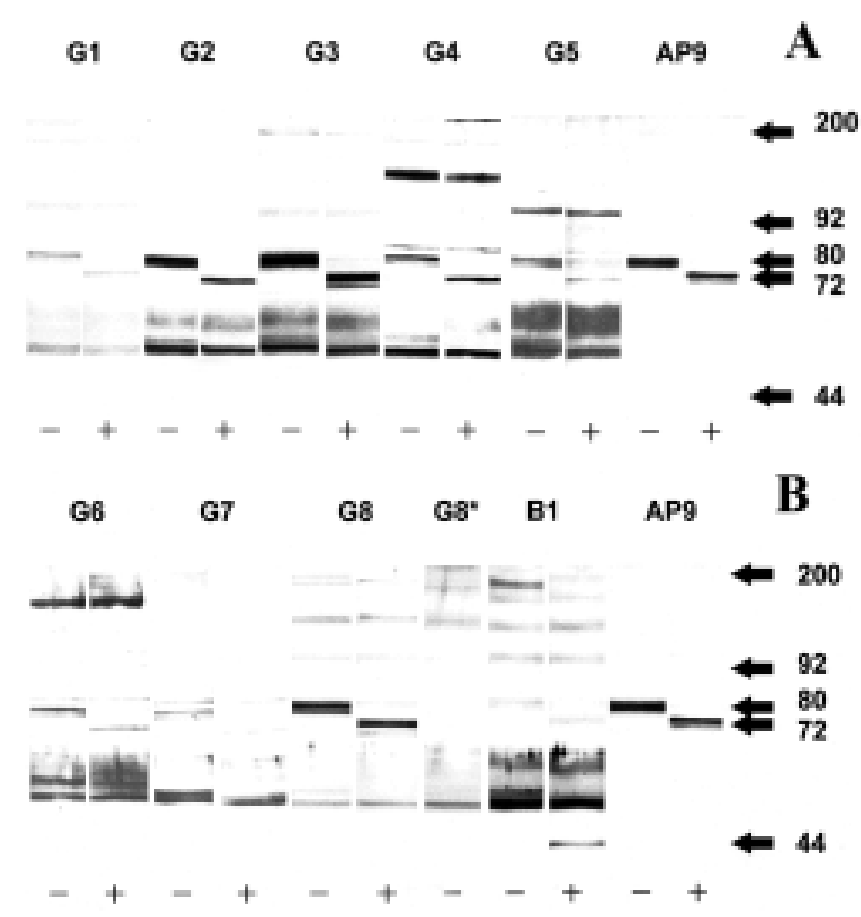

Fig. 1 Immunoblotting of inhibitor plasmas with FVIII polypeptides. The binding specificity of inhibitor plasmas from hemophilic German patients $\mathrm{G} 1$ to G8 (Table 1) was determined by immunoblotting before (-) and after (+) thrombin activation of FVIII-SD as described in Materials and Methods and shown in panels A and B. Patient B1 (panel B) served as a PUP control. Lane G8* (panel B) shows the reactivity of G8 plasma after disappearance of the inhibitor titer. Lanes AP9 are the rabbit anti fVIII 1797-1815 antibody controls for detection of $80 \mathrm{kDa}$ light chain and $72 \mathrm{kDa}$ thrombin cleaved light chain. The molecular weight markers of $\mathrm{kDa}$ are shown by the arrows in all figures 


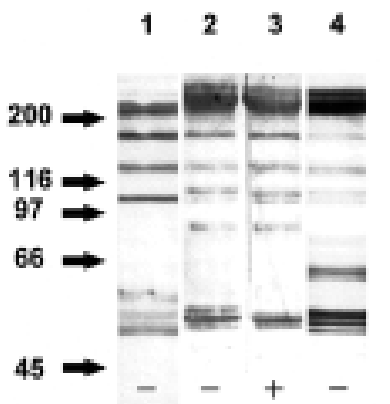

Fig. 2 Immunoblotting of FVIII-SD with a normal plasma pool and anti vWf MoAb. The polypeptides were incubated with a pooled normal plasma (lane 1) or an anti vWf MoAb, QED 10103 (lanes 2, 3) before and after thrombin activation, respectively, and analyzed as in Fig. 1. Lane 4 shows FVIII-SD polypeptides stained by Coomassie blue

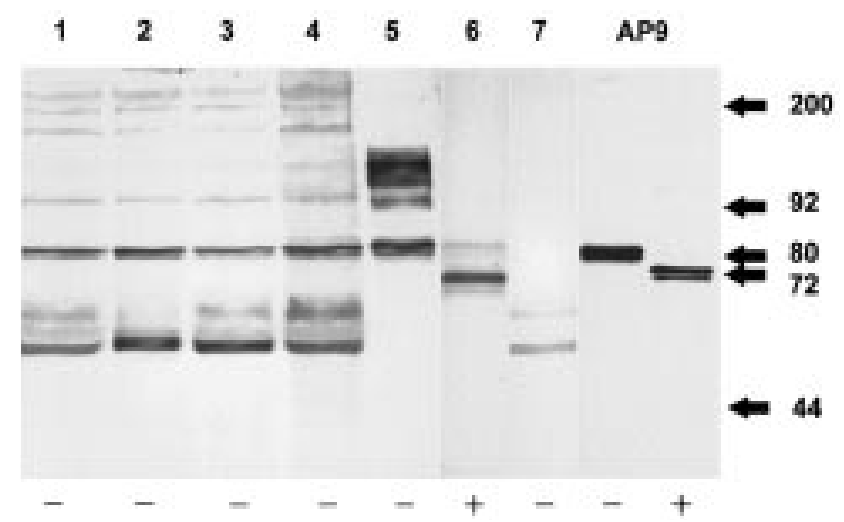

Fig. 3 Immunoblotting of an inhibitor plasma pool with different FVIII concentrates. Plasma FVIII concentrates (2 IU/lane) are as follows in lanes 1-4: FVIII-SD, FVIII-THP, Haemoctin, FVIII-SDP (Bisinact), and lanes 5-6: recombinant FVIII before (-) and after (+) thrombin activation, respectively. Lane 7 is a control of FVIII-SD without inhibitor plasma. The proteins were resolved by SDS-PAGE and analyzed by immunoblotting as in Fig. 1 with a pool of 3 inhibitor plasmas. Antibody AP9 is described in Fig. 1

could not be distinguished in efficacy of treatment or in inibitor induction, the term FVIII-SDP (solvent-detergent pasteurized) will be used for simplicity, and the earlier unpasteurized product will be referred to as FVIII-SD. FVIII-SDP was treated with solvent-detergent followed by ion exchange chromatography and heat pasteurization at $63^{\circ} \mathrm{C}$ for $10 \mathrm{~h}$ in the presence of a high concentration of stabilizers. Inhibitors to FVIII-SDP appeared after 84-300 exposure days, but they disappeared and fVIII recovery was normalized when FVIII-SDP was replaced by other fVIII concentrates.

Patient B1, a severe hemophilia A patient, was treated exclusively with FVIII-THP in a Brussels Hemophilia Center (Hôpital Brugmann), and he developed a high titer inhibitor in 144 exposure days. Patient B1 plasma was used as a control, as the inhibitor developed under conditions usually seen for previously untreated patients (PUPs).

Epitope specificity of patient anti fVIII antibodies by immunoblotting. Plasma from the patients with FVIII-SDP induced inhibitors was tested for epitope specificity after SDS-PAGE of a single batch of FVIII-SD and immunoblotting. In Figs. $1 \mathrm{~A}$ and 1B, specific immunoreaction of plasmas from patients G1-G8 was detected for the $80 \mathrm{kDa}$ light chain. Upon thrombin cleavage, binding to the $80 \mathrm{kDa}$ fragment was greatly decreased or absent, concomitant with the detection of the expected $72 \mathrm{kDa}$ fragment lacking the amino-terminal light chain polypeptide, amino acids $1649-1689$. The $80 \mathrm{kDa}$ and $72 \mathrm{kDa}$ fragments were identified by binding of AP9 (Figs. 1A, 1B, lane AP9), a rabbit antibody specific for peptide 1797-1815 of the A3 domain. Identical results were obtained when FVIII-SDP was used (data not shown).

No antibody binding to the $92 \mathrm{kDa}$ heavy chain or its thrombin cleavage fragments of $44 \mathrm{kDa}$ (A2 domain) or $54 \mathrm{kDa}$ fragment (A1 domain) was detected. The bands migrating above the $92 \mathrm{kDa}$ marker are not likely to be fVIII related as their position did not change after thrombin cleavage. This was verified by the AP9 control of rabbit anti human fVIII light chain in which no bands larger than $80 \mathrm{kDa}$ or smaller than $72 \mathrm{kDa}$ were observed. G8 plasma drawn five months after the inhibitor episode did not bind to $80 \mathrm{kDa}$ light chain, demonstrating the disappearance of these antibodies (Fig. 1B, lane G8*). The immunoblotting results demonstrate that the anti fVIII antibodies of patients G1-G8 bind only to the uncleaved or thrombin cleaved light chains of both FVIII-SD and FVIII-SDP. A new antibody epitope was thus probably not induced by the heat pasteurization.

The anti fVIII antibodies of PUP B1 (Fig. 1B, lanes 8, 9) appeared after treatment by FVIII-THP, and they recognized the $80 \mathrm{kDa}$ and $72 \mathrm{kDa}$ light chain fragments as well as the $44 \mathrm{kDa}$ A2 domain heavy chain fragment. This specificity of the B1 antibodies is more similar to that seen in severe hemophilic PUPs treated with various other fVIII concentrates (9), and it is different from that of the antibodies elicited by FVIII-SDP.

A sample from a plasma pool of 3200 normal donors was used as a specificity control, as protein bands other than fVIII were apparent in the immunoblots. No binding of the pool to the FVIII-SDP 80 or $72 \mathrm{kDa}$ fragments was detectable (Fig. 2, lane 1), which confirmed the specificity of the inhibitor plasmas for these fragments (Fig. 1). Four polypeptides of $220,170,130$, and $100 \mathrm{kDa}$ and several of 50 to $55 \mathrm{kDa}$ were also detected. Binding of control anti vWf MoAb QED 10103 demonstrated that $\geq 3$ polypeptides $\geq 100 \mathrm{kDa}$ comigrated with $\mathrm{vWf}$ specific polypeptides present in FVIII-SD with $(+)$ or without (-) thrombin cleavage (Fig. 2, lanes 2,3). This is consistent with the fact that vWf makes up $40 \%$ of the total protein of FVIII-SD. Several bands in FVIIISD stained with Coomassie blue (lane 4) and some bands in the inhibitor immunoblots comigrated with the vWf polypeptides. These results suggest that both normal individuals and the hemophiliacs in this study have low levels of anti vWf antibodies. The variability among the patients in their detection of the proposed vWf bands (Figs. 1A and 1B) may indicate a corresponding variability in the specificity of their antibodies for the different vWf fragments. We did not detect any modification in vWf activity, vWf antigen, or multimer composition (results not shown).

Inhibitor immunoreactivity towards different FVIII concentrates. The epitope specificity of the inhibitors induced by FVIII-SDP was compared for fVIII concentrates Recombinate, FVIII-SD, FVIII-THP, Haemoctin, and FVIII-SDP. In Fig. 3, lanes 1-4, the $80 \mathrm{kDa}$ light chain was recognized in all the concentrates by immunoblots with a plasma pool from three of the German patients. No additional immunospecificity was observed when two batches of FVIII-SDP associated with inhibitor induction were used (not shown). Inhibitor reactivity toward Recombinate $80 \mathrm{kDa}$ and $72 \mathrm{kDa}$ fragments was observed before (lane 5) and after thrombin proteolysis (lane 6), respectively, demonstrating that the binding was specific for the light chain as well. As Recombinate contains no significant protein contaminants, the $>97 \mathrm{kDa}$ detected bands are also fVIII specific. As it would be difficult to distinguish the fVIII from the vWf bands, we have not further pursued why these bands do not also appear in FVIII-SDP immunoblots. 


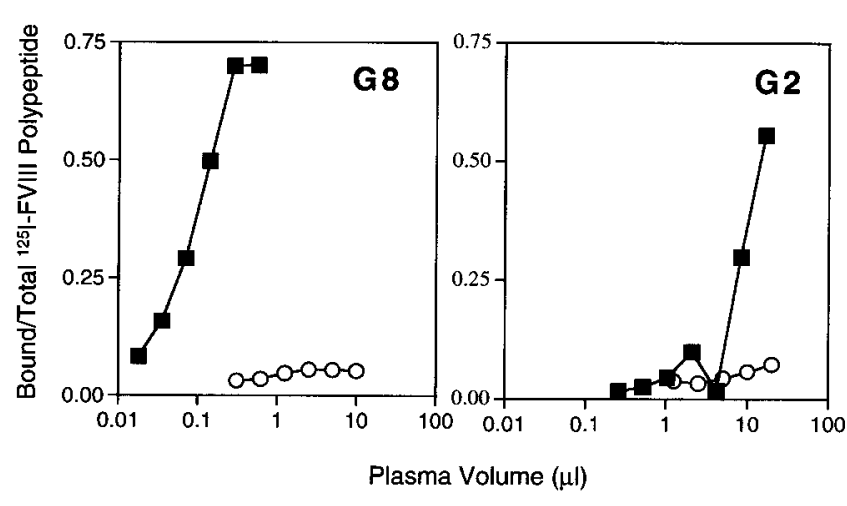

Fig. 4 Anti-fVIII antibody binding to heavy chain and C2 domain in radioimmunoprecipitation assays. Details are described in Materials and Methods. Serial two-fold dilutions of patient G2 and G8 plasmas were tested for binding to the $\mathrm{C} 2$ domain $(\square)$ and the heavy chain $(\bigcirc)$. The plasma volume per total volume of $60 \mu \mathrm{l}$ is shown on the $\mathrm{x}$ axis

Table 3 Summary of inhibitor plasma characterization

\begin{tabular}{|c|c|ccc|}
\hline $\begin{array}{c}\text { Patient } \\
\text { Number }\end{array}$ & $\begin{array}{c}\text { Bethesda } \\
\text { units/ml }\end{array}$ & \multicolumn{3}{|c|}{ Immunoprecipitation units/ml } \\
& & Heavy chain & C2 & C2/HCh \\
\hline G1 & 2.1 & 0 & 10.6 & -10.6 \\
G2 & 4.0 & 3.4 & 40.5 & 11.9 \\
G3 & 3.4 & 36.0 & 870 & 24 \\
G4 & 2.9 & 5.0 & 577 & 115 \\
G8 & 211 & 33.0 & 4892 & 148 \\
\hline
\end{tabular}

IP units $/ \mathrm{ml}$ were calculated as described in Materials and Methods.

A control without inhibitor plasma is shown in lane 7. The visible bands in this lane are probably due to the presence of the $\operatorname{IgG}(<0.1 \mathrm{mg})$ in the concentrate and its detection by the goat anti human IgG used for detection. The patient bands in this region were probably stronger due to the additional binding to vWf fragments of this size (Fig. 2).

Determination of $C 2$ domain specificity of the anti-fVIII antibodies by immunoprecipitation and inhibitor neutralization assays. We performed immunoprecipitation assays with highly purified, radiolabeled fragments of plasma derived fVIII to further define the domain specificity of the anti fVIII antibodies. Representative dose response binding curves to heavy chain and C2 domain by G2 and G8 plasmas are shown in Fig. 4, and IP units/ml were calculated (Materials and Methods) from the linear portion of such curves for plasmas G1-G4 and G8 (Table 3). Insufficient plasma was available to test the others. The IP units $/ \mathrm{ml}$ for heavy chain were 11 to 148 -fold lower than those for C2. As the immunoblots (Figs. 1-3) contained a number of bands $>80 \mathrm{kDa}$ that were stained, the IP results more clearly confirm that anti heavy chain antibody titers are very low or negative. Nonquantitative IP assays of antibody binding to the ${ }^{35} \mathrm{~S}-\mathrm{A} 3-\mathrm{C} 1$ portion of the light chain (Fig. 5) indicated the barely detectable binding by the inhibitor plasmas (1:5 dilution) compared to anti A3 MoAb CLB-CAg A (19), which is present at saturating concentrations (lane 1), confirming that the antibodies bound primarily to the $\mathrm{C} 2$ domain of the light chain.

Inhibitor neutralization by purified light chain and the A2 and C2 domains was performed. Increasing concentrations of C2 and light chain both led to complete neutralization of the inhibitor titer (Fig. 6). As equimolar concentrations of each were required for neutralization, the antibodies appear to bind to each with similar affinity, and binding

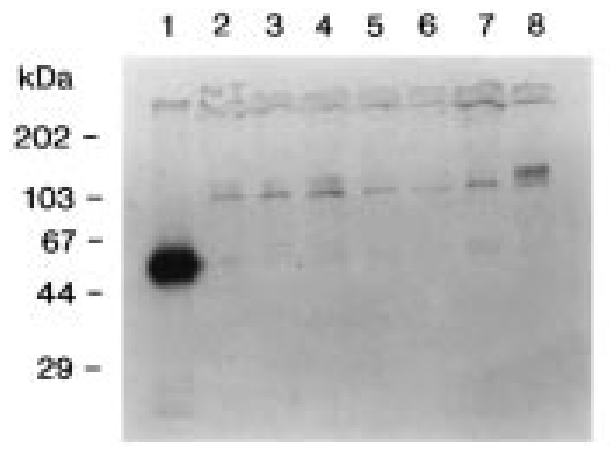

Fig. 5 Inhibitor antibody binding to A3-C1 by immunoprecipitation. Details are described in Materials and Methods. Analysis was by SDS-10\% PAGE and autoradiography. Lanes 1-8 are anti A3 MoAb CLB-CAg A, G1, G3, G4, G5, G6, G7, and G8, respectively

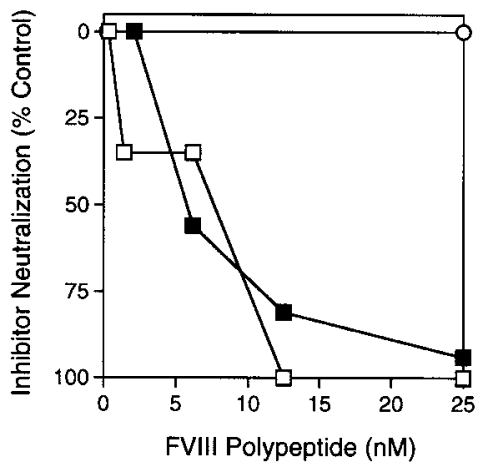

Fig. 6 Inhibitor neutralization assay of G8 plasma by fVIII polypeptides. Increasing concentrations of light chain $(\mathbf{\square}), \mathrm{C} 2$ domain $(\square)$, and A2 domain $(\bigcirc)$ were added to the same dilution of G8 plasma, and the inhibitor titers and \% neutralization were determined as described in Methods. The A2 domain at $50 \mathrm{nM}$ also had no effect (not shown)

is restricted to the $\mathrm{C} 2$ domain as also demonstrated by their minimal binding to $\mathrm{A} 3-\mathrm{C} 1$ (Fig. 5). The A2 domain did not neutralize the inhibitors at concentrations up to $50 \mathrm{nM}$.

\section{Disc ussion}

The development of anti fVIII antibodies is a serious complication in the treatment of hemophilia A patients with fVIII concentrates. Patients with severe hemophilia are most likely to develop inhibitors as they are not tolerant to fVIII, but only about $25 \%$ of them have such antibodies during the course of their treatment (20). The absence of fVIII and some gene mutations such as the intron 22 inversion (21) are important factors for the pathogenesis of inhibitor formation. A weaker association is the HLA class II genotype (22). Our results emphasize in addition the potential effect of changes in the biochemical and structural integrity of the fVIII molecule in inducing inhibitors in hemophiliacs (PTP) that were previously tolerant to fVIII infusion.

From December 1994 to September 1995, 12 multitransfused patients in Germany and 8 patients in Belgium developed inhibitors after treatment with new fVIII concentrates, Octavi SDPlus in Germany and Bisinact in Belgium, which we refer to as FVIII-SDP. The production process of FVIII-SDP included two viral inactivation steps: solventdetergent treatment and pasteurization at $63^{\circ} \mathrm{C}$ for $10 \mathrm{~h}$. A similar outbreak of product related inhibitors was detected in 1990 to 1991 in pre- 
viously treated hemophiliacs who received fVIII CPS-P, another concentrate that was heat pasteurized $\left(60^{\circ} \mathrm{C}\right.$ for $\left.10 \mathrm{~h}\right)$. The exact reason why these concentrates became immunogenic is unknown and still under investigation.

In the present study we demonstrated that the inhibitors induced by FVIII-SDP in German hemophilic patients had an epitope specificity restricted to the $72 \mathrm{kDa}$ thrombin cleaved light chain in immunoblotting assays, as did the inhibitors from the previously tested Belgian patients (6). In the only German patient with a high inhibitor titer, inhibitor neutralization assays demonstrated that these antibodies were directed solely against the C2 domain of the fVIII light chain. The other 4 patients could not be similarly analyzed due to their lower inhibitor titers, but it was evident from radioimmunoprecipitation assays of all $5 \mathrm{pa}-$ tients with the fVIII heavy chain, the $\mathrm{C} 2$ domain, and the A3-C1 domains that $\geq 90 \%$ of all anti-fVIII antibodies bound to $\mathrm{C} 2$. In contrast, patient B1, a PUP who developed inhibitors against FVIII-THP which had only a solvent-detergent viral inactivation step, had both anti heavy chain and anti light chain antibodies, which is common for hemophilic inhibitors (9).

As the C2 domain restricted epitope specificity was identical to those of the FVIII CPS-P induced inhibitors (8), it was possible that heat pasteurization was the sole cause of the inhibitor outbreak in both cases. However, as only some lots of FVIII-SDP were associated with inhibitor formation, this is unlikely. In addition, no other pasteurized fVIII concentrates used for treatment of hemophilia were associated with inhibitor formation in PTP. The inhibitors induced by FVIII-SDP recognized several different fVIII concentrates with similar specificity, suggesting that FVIII-SDP immunogenicity, similarly to that of FVIII CPS-P, was not due to the appearance of novel antibody binding sites (8).

Recent unpublished results obtained in our laboratory suggested an alteration of biological properties of the FVIII-SDP light chain such that thrombin activation occurred more slowly but factor Xa generation and phospholipid binding were enhanced (23). Additional data in one study suggested the association of inhibitor development with the presence of a proteolytic $40 \mathrm{kDa}$ FVIII-SDP fragment generated prior to pasteurization (24). In another study this fragment was present in a batch of FVIII-SDP strongly associated with the appearance of inhibitors (25). As the $40 \mathrm{kDa}$ fragment was also found in other batches, a definitive conclusion for the role of this fragment in the novel immunogenicity of FVIII-SDP was not possible.

Although a neonatal mouse tolerance induction model was previously used to determine if B domain deleted fVIII was immunologically different from intact fVIII, this could not be demonstrated (26). It is also not clear whether this model is capable of detecting the increased immune responsiveness of partially altered molecules such as FVIII-SDP. The more recently developed hemophilic mice with a knockout of the fVIII gene (27) may prove to be a more useful immunogenicity model. For the present, no in vitro or animal model can be used to assure the immunological safety of a new fVIII concentrate. The inhibitor induction by FVIII-SDP and FVIII CPS-P stresses the need for future investigations in this direction and clinical trials in hemophilic PTP without inhibitors when a new fVIII concentrate is to be evaluated.

\section{Acknowledgments}

We are grateful to M. C. Baelden for excellent technical assistance. This study was supported by research convention 96B14 from the "Région de Bruxelles-Capitale" (R. L.) and by grant RO1 HL55273 from the National Institutes of Health, Bethesda, MD, USA (D. S.).

\section{References}

1. Bray GL, Gomperts ED, Courter S, Gruppo R, Gordon EM, Manco-Johnson M, Shapiro A, Scheibel E, White G III, Lee M, and the Recombinate Study Group. A multicenter study of recombinant factor VIII (Recombinate): Safety, efficacy, and inhibitor risk in previously untreated patients with hemophilia A. Blood 1994; 83: 2428-35.

2. Rosendaal FR, Nieuwenhuis HK, van den Berg HM, Heijboer H, MauserBunschoten EP, van der Meer J, Smit C, Strengers PFW, Briët E, and the Dutch Hemophilia Study Group. A sudden increase in factor VIII inhibitor development in multitransfused hemophilia A patients in The Netherlands. Blood 1993; 81: 2180-6.

3. Peerlinck K, Arnout J, Gilles JG, Saint-Remy J-M, Vermylen J. A higher than expected incidence of factor VIII inhibitors in multitransfused haemophilia A patients treated with an intermediate purity pasteurized factor VIII concentrate. Thromb Haemost 1993; 69: 115-8.

4. Mauser-Bunschoten EP, Rosendaal FR, Nieuwenhuis HK, Roosendaal G, Briët E, van den Berg HM. Clinical course of factor VIII inhibitors developed after exposure to a pasteurised Dutch concentrate compared to classic inhibitors in hemophilia A. Thromb Haemost 1994; 71: 703-6.

5. Mannucci PM, Santagostino E, Di Bona E, Gentili G, Ghirardini A, Chiavoni M, Mele A. The outbreak of hepatitis A in Italian patients with hemophilia: facts and fancies. Vox Sang 1994; 67: 31-5.

6. Peerlinck K, Arnout J, Di Giambattista M, Gilles JG, Laub R, Jacquemin M, Saint-Remy JMR, Vermylen J. Factor VIII inhibitors in previously treated haemophilia A patients with a double-virus inactivated plasma derived factor VIII concentrate. Thromb Haemost 1997; 77: 80-6.

7. Vehar GA, Keyt B, Eaton D, Rodriguez H, O'Brien DP, Rotblat F, Oppermann H, Keck R, Lawn RM, Capon DJ. Structure of human factor VIII. Nature 1984; 312: 337-42.

8. Sawamoto Y, Prescott R, Zhong D, Saenko EL, Mauser-Bunschoten E, Peerlinck K, van den Berg M, Scandella D. Dominant C2 domain epitope specificity of inhibitor antibodies elicited by a heat pasteurized product, factor VIII CPS-P, in previously treated hemophilia A patients without inhibitors. Thromb Haemost 1998; 79: 62-8.

9. Prescott R, Nakai H, Saenko EL, Scharrer I, Nilsson IM, Humphries J, Hurst D, Bray G, Scandella D. The inhibitor antibody response is more complex in hemophilia A patients than in most nonhemophiliacs with factor VIII autoantibodies. Blood 1997; 89: 3663-71.

10. Vlot AJ, Koppelman SJ, van den Berg MH, Bouma BN, Sixma JJ. The affinity and stoichiometry of binding of human factor VIII to von Willebrand factor. Blood 1995; 85: 3150-7.

11. Nesheim M, Pittman DD, Giles AR, Fass DN, Wang JH, Slonosky D, Kaufman RJ. The effect of plasma von Willebrand factor on the binding of human factor VIII to thrombin-activated human platelets. J Biol Chem 1991; 266: 17815-26.

12. Kasper CK, Aledort LM, Counts RB, Edson JR, Fratantoni J, Green D, Hampton JW, Hilgartner MW, Lazerson J, Levine PH, et al. A more uniform measurement of factor VIII inhibitors. Thrombos Diathes Haemorrh 1975; 34: 869-72.

13. Scandella D, Timmons L, Mattingly M, Trabold N, Hoyer LW. A soluble recombinant factor VIII fragment containing the A2 domain binds to some human anti-factor VIII antibodies that are not detected by immunoblotting. Thromb Haemost 1992; 67: 665-71.

14. Saenko EL, Scandella D. A mechanism for inhibition of factor VIII binding to phospholipid by von Willebrand factor. J Biol Chem 1995; 270: 13826-33.

15. Scandella D, Mattingly M, Prescott R. A recombinant factor VIII A2 domain polypeptide quantitatively neutralizes human inhibitor antibodies which bind to A2. Blood 1993; 82: 1767-75.

16. Zhong D, Saenko EL, Felch M, Scandella D. Some human inhibitor antibodies interfere with factor VIII binding to factor IX. Blood 1998; 92 : $136-42$.

17. Thompson AR, Murphy MEP, Liu ML, Saenko EL, Healey JF, Lollar P, Scandella D. Loss of tolerance to exogenous and endogenous factor VIII in 
a mild hemophilia A patient with an $\operatorname{Arg}^{593}$ to Cys mutation. Blood 1997; 90: 1902-10.

18. Toole JJ, Knopf JL, Wozney JM, Sultzman LA, Buecker JL, Pittman DD, Kaufman RJ, Brown E, Shoemaker C, Orr EC, et al. Molecular cloning of a cDNA encoding human antihaemophilic factor. Nature 1984; 312: 342-7.

19. Lenting PJ, van de Loo JHP, Donath M-JSH, van Mourik JA, Mertens K. The sequence Glu1811-Lys1818 of human blood coagulation factor VIII comprises a binding site for activated factor IX. J Biol Chem 1996; 271 : 1935-40.

20. Hoyer LW. The incidence of factor VIII inhibitors in patients with severe hemophilia A. Adv Exp Biol Med 1995; 386: 35-45.

21. Schwaab R, Brackmann H-H, Meyer C, Seehafer J, Kirchgesser M, Haack A, Olek K, Tuddenham EGD, Oldenburg J. Haemophilia A: Mutation type determines risk of inhibitor formation. Thromb Haemost 1995; 74: 1402-6.

22. Hay CRM, Ollier W, Pepper L, Cumming A, Keeney S, Goodeve AC, Colvin BT, Hill FGH, Preston FE, Peake IR, et al. HLA class II profile: a weak determinant of factor VIII inhibitor development in severe haemophilia A. Thromb Haemost 1997; 77: 234-7.
23. Raut S, Di Giambattista M, Bevan SA, Hubbard AR, Barrowcliffe TW, Laub R. Modification of FVIII in therapeutic concentrates after virus inactivation by solvent-detergent and pasteurisation. Thromb Haemost 1998; 80: 624-31.

24. Josic D, Stadler M, Buchacher A, Pock K, Robinson S, Schwinn H. Degradation products of factor VIII which can lead to increased immunogenicity. Thromb Haemost 1997; Suppl.: 576.

25. Rosendaal FR. Factor VIII inhibitors on a SD-treated and pasteurized concentrate associated with specific batches and batch characteristics. Thromb Haemost 1997; Suppl.: 590.

26. Pittman DD, Alderman EM, Tomkinson KN, Wang JH, Giles AR, Kaufman RJ. Biochemical, Immunological, and In Vivo Functional Characterization of B-Domain-Deleted Factor VIII. Blood 1993; 81: 2925-35.

27. Bi L, Lawler AM, Antonarakis SE, High KA, Gearhart JD, Kazazian HH, Jr. Targeted disruption of the mouse factor VIII gene produces a model of haemophilia A. Nature Genet 1995; 10: 10119-21.

Received May 4, 1998 Accepted after revision September 15, 1998

\section{Ordering has never been so easy:}

\section{http:// www,schattauer.com}

